\title{
Perinatal Hypoxia and Ischemia in Animal Models of Schizophrenia
}

\author{
Dimitri Hefter ${ }^{1,2}$, Hugo H. Marti ${ }^{3}$, Peter Gass ${ }^{1}$ and Dragos Inta ${ }^{1,4 *}$ \\ ${ }^{1}$ RG Animal Models in Psychiatry, Department of Psychiatry and Psychotherapy, Medical Faculty Mannheim, Central Institute \\ of Mental Health, University of Heidelberg, Heidelberg, Germany, ${ }^{2}$ RG Neuro- and Sensory Physiology, Institute of \\ Physiology and Pathophysiology, University of Heidelberg, Heidelberg, Germany, ${ }^{3}$ RG Neurovascular Research, Institute of \\ Physiology and Pathophysiology, University of Heidelberg, Heidelberg, Germany, ${ }^{4}$ Department of Psychiatry, University of \\ Basel, Basel, Switzerland
}

Intrauterine or perinatal complications constitute a major risk for psychiatric diseases. Infants who suffered from hypoxia-ischemia $(\mathrm{HI})$ are at twofold risk to develop schizophrenia in later life. Several animal models attempt to reproduce these complications to study the yet unknown steps between an insult in early life and outbreak of the disease decades later. However, it is very challenging to find the right type and severity of insult leading to a disease-like phenotype in the animal, but not causing necrosis and focal

OPEN ACCESS

Edited by:

Alessandro Guidotti, University of Illinois at Chicago, United States

Reviewed by: Olivier Civelli, University of California, Irvine, United States Sabina Berretta, McLean Hospital, United States

*Correspondence: Dragos Inta dragos.inta@upkbs.ch, dragos.inta@zi-mannheim.de

Specialty section: This article was submitted to Schizophrenia

a section of the journal

Frontiers in Psychiatry

Received: 06 December 2017 Accepted: 16 March 2018 Published: 29 March 2018

Citation:

Hefter D, Marti HH, Gass $P$ and Inta $D$ (2018) Perinatal Hypoxia and

Ischemia in Animal Models of Schizophrenia.

Front. Psychiatry 9:106. doi: 10.3389/fpsyt.2018.00106 neurological deficits. By contrast, too mild, repetitive insults may even be protective via conditioning effects. Thus, it is not surprising that animal models of hypoxia lead to mixed results. To achieve clinically translatable findings, better protocols are urgently needed. Therefore, we compare widely used models of hypoxia and $\mathrm{HI}$ and propose future directions for the field.

Keywords: perinatal, hypoxia, schizophrenia, ischemia, animal models, neurodevelopment, vannucci

\section{INTRODUCTION}

Schizophrenia $(\mathrm{Sz})$ is a severe psychiatric disease affecting approximately $1 \%$ of world population. Sz patients suffer from positive symptoms such as delusions and hallucinations, negative symptoms including affective flattening and social withdrawal as well as cognitive deficits (1). While the disease usually manifests in late adolescence or young adulthood, it is commonly assumed that insults lay its pathophysiological foundation already early in development (2). Intrauterine or perinatal hypoxia-ischemia (HI) is a well-known epidemiological risk factor for $\mathrm{Sz}$, increasing the hazard ratio twofold (3). Young brains react highly plastic to transient hypoxic insults below apoptotic threshold (4). Several hundred genes are known to be upregulated in response to hypoxia and trophic factors such as BDNF are secreted. In genetically predisposed individuals, this neuroprotective response may be compromised, rendering their brain more vulnerable to $\mathrm{HI}$ insults $(5,6)$. While a healthy infant may fully recover from mild transient $\mathrm{HI}$, an insult of similar severity in an infant with a compromised neuroprotective response may cause long-lasting deficits. Indeed, many Sz-associated genes are involved in $\mathrm{HI}$ responses (7), and fetuses at high risk for psychosis appear to be more vulnerable to hypoxia (8). If only most vulnerable cell populations are affected and the functional alterations are subtle, they may result in a subclinical phenotype with an intrinsically higher vulnerability to environmental and pharmacological stress. Exposure to such stress in adult life ultimately leads to clinical manifestation (9). However, the steps between an early-life insult and the outbreak of the disease decades later are unknown. To advance beyond hypotheses and dissect the underlying mechanisms, proper animal models of perinatal HI are needed. They are required to reliably resemble the human condition as closely as possible including neurophysiological alterations similar 
to those in patients and a psychosis-like phenotype. In this article, we discuss the models currently employed in the field and point out possible future directions.

\section{HI MODELS FOR PSYCHIATRIC RESEARCH}

\section{Important Considerations for the Design of the Study}

The attempts to achieve clinically translatable results are hampered by the challenge to titrate the desired insult severity according to the vulnerability of the studied system. Depending on the condition to be modeled, deficits ranging from subtle functional alterations to wide-spread necrosis may be pursued. The latter can be relatively easily evaluated by common histological means and neurological signs. The detection of former, however, as needed in Sz models, requires a careful choice of specific readout parameters.

\section{Parameters Affecting Insult Severity}

In $\mathrm{HI}$ models of $\mathrm{Sz}$, the insult needs to be severe enough to elicit chronic measurable functional deficits, without causing widespread necrosis and focal neurological deficits. On the other hand, repetitive mild HI may lead to conditioning effects, which increase the resilience to further stress (10). The severity of the HI insult depends on the following parameters: oxygen $\left(\mathrm{O}_{2}\right)$ concentration and composition of the atmosphere, duration of hypoxia/ anoxia, presence or absence of ischemia, and presence or absence of an adaptation period. While anoxia and severe hypoxia below $4 \% \mathrm{O}_{2}$ can be survived for only several minutes, milder hypoxia between 6 and 12\% $\mathrm{O}_{2}$ can be tolerated for considerably longer periods of time (as up to days or weeks), especially if the insult is preceded by an adaptation period (11). Interestingly, there is a difference between anoxia with $100 \% \mathrm{~N}_{2}$ vs. anoxia with $100 \%$ $\mathrm{CO}_{2}$ in the atmosphere, the latter causing a stronger release of free radicals as shown in mice on their first postnatal day (P1) (12). If ischemia is induced additionally to hypoxia, the tolerance time may be dramatically shortened; thus, the insult duration should be adjusted.

\section{Parameters Affecting System Vulnerability}

Fundamental differences between species need to be carefully considered. Although mammals including pigs, sheep, and primates may reassemble human condition more closely, rodents are the most common model organisms in HI research. But even in ontogenetically related species such as mice and rats, the same kind of insult can lead to very different peripheral and CNS responses $(13,14)$. As preterm or perinatal insults are considered as risk factors of $\mathrm{Sz}$, the insult needs to be administered at the according developmental age. During the first two postnatal weeks, the CNS in rodents is highly dynamic and differently reacts to environmental insults (15). Methods to translate the developmental age across different species have been developed (16). According to this model, the CNS of a P7-P8 mouse pup developmentally corresponds to a preterm infant in the third trimester. This period is crucial for dendritic outgrowth, synapse formation, maturation of neurons, and interneurons particularly (17). Furthermore, synchronized network function in form of rapidly evolving oscillations emerges at this age (17). They are accompanied by fundamental changes in synaptic transmission such as the switch of NMDA receptor (NMDAR) subunits GluN2B to GluN2A (18) and the transition of the excitatory to inhibitory action of GABA (17). Thus, it is plausible that such fundamental features may dramatically influence neuronal vulnerability. Differences in the development of brain areas and cell types also need to be taken into account (16). Furthermore, strain $(19)$ and sex $(20,21)$ differences need to be considered. The vulnerability to HI highly differs between brain areas and cell types (22). Thus, hippocampal CA1 pyramidal cells belong to the most susceptible neurons, while the granule cells in the dentate gyrus are very resistant to $\mathrm{HI}$ insults (23). Parvalbuminexpressing fast-spiking interneurons are also regarded as highly vulnerable to $\mathrm{HI}$ damage due to their high energy demand (24), although the available data are conflicting, possibly due to the heterogeneity of these neurons $(25,26)$. Last but not least, peripheral factors such as body temperature, respiratory reserve, cardiovascular regulatory mechanisms, blood composition, immune and hormonal response, and environmental cofactors affect the vulnerability of the organism and should be controlled for as thoroughly as possible as they may fundamentally influence the outcome (27-30).

\section{Important Readout Parameters for Sz Research}

Proper readout parameters for Sz-like alterations on anatomical, functional, and behavioral level need to be carefully selected. On the behavioral level, increased locomotion, stereotypical movements, hyperirritability, deficits in social interaction, various cognitive deficits, and sensorimotor gating deficits following perinatal HI are implied to represent a psychosis-like phenotype in rodents analogous to clinical symptoms of $\mathrm{Sz}$ (31). Similar to $\mathrm{Sz}$ patients, rodents exposed to HI exhibit increased sensitivity to stimulants such as amphetamines, while antipsychotics ameliorate many of their deficits (31). However, behavioral studies in rodents are naturally limited as they will never fully represent the wide range of human symptoms. Furthermore, the specificity of a behavioral phenotype needs to be critically scrutinized since the partial overlap of phenotypes in models of different psychiatric diseases cannot be neglected (32). To improve construct validity of animal models, it is therefore crucial to underpin a behavioral phenotype by pathophysiological and anatomical traits that characterize the specific human disorder. Importantly, HI models display several such traits of Sz. Thus, perinatal HI leads to cortical thinning, ventriculomegaly, and reduced hippocampal volume (33), all findings present in $\mathrm{Sz}$ patients (34-36). Furthermore, HI induces cell loss in hippocampal CA1 and CA3. Reduced hippocampal volume correlates with the severity of positive symptoms and required antipsychotics dosage (37). These anatomical changes are accompanied by functional deficits including disrupted communication between large cortical networks $(38,39)$, altered cortical oscillations (40,41), and sensorimotor gating deficits (42). Novel electrophysiological and imaging techniques confirmed the presence of these endophenotypes in rodent models (42-44). Loss and/or malfunction of 
GABA-ergic interneurons, particularly parvalbumin-expressing fast-spiking interneurons, is considered a hallmark of $\mathrm{Sz}$ on the cellular level $(45,46)$ and provides a simple and important histological readout in animal models. On the molecular level, NMDAR hypofunction and hyperdopaminergia are considered to underlie $\mathrm{Sz}$ pathophysiology $(47,48)$. Expression, structure, and function of glutamate and dopamine receptors are therefore important objects of study with electrophysiological and molecular biological methods. HI indeed was found to induce changes in glutamatergic and dopaminergic transmission (49). In summary, a multiple-scale approach employing a combination of different techniques should be used to detect $\mathrm{Sz}$-characteristic changes in cellular, network, and whole-brain functions.

\section{Common Experimental Paradigms}

The common animal models can be divided into two major groups: pure hypoxia and combined HI models. The first group can be further subdivided into chronic intermittent, chronic continuous and acute hypoxia ( $\mathrm{AH}) /$ anoxia models. Hypoxia is usually achieved by placing the animal into a sealed chamber where the atmosphere content can be precisely regulated with a gas delivery system. In this article, we will focus on four commonly used types of models in rodents and will omit discussion of rarer models such as asphyxia or submersion as well as models in other species.

\section{Chronic-Intermittent Hypoxia (CIH)}

In $\mathrm{CIH}$ models, the animals are intermittently exposed to hypoxia of usually $6-10 \% \mathrm{O}_{2}$ on several consecutive days. This relatively mild insult usually leads to subtle functional and behavioral alterations without presence of necrotic cell death. A paradigm employing a $6-18 \mathrm{~h}$ hypoxia $\left(11 \% \mathrm{O}_{2}\right)$-normoxia cycle in $\mathrm{P} 4-\mathrm{P} 8$ rats led to prepulse inhibition deficits (a measure of sensorimotor gating deficient in Sz patients) and locomotor deficits (regarded as a correlate of positive symptoms) (50). This syndrome was reversed by clozapine (51). These deficits correlated with altered expression of the NMDAR and various synaptic proteins $(26,50)$. In another study employing a similar paradigm, $\mathrm{CIH}$ led to impairments in hippocampal long-term plasticity that was rescued by BDNF administration (26). A CIH model with $10 \% \mathrm{O}_{2}, 5 \% \mathrm{CO}_{2}$, and $85 \% \mathrm{~N}_{2}$ in P7-P11 rats led to long-lasting hyperlocomotion, working memory impairments, and circadian rhythm abnormalities that were accompanied by upregulation of striatal D1 receptors (52). Altered dopaminergic function in animal models corresponds to findings in human neonates and may lay a pathophysiological foundation for Sz in later life (53). In contrast to these results, a study conducted by our group did not find protracted behavioral abnormalities after $\mathrm{CIH}$ with $10 \%$ $\mathrm{O}_{2} 6 \mathrm{~h}$ /day in P3-P7 mice (54). This lack of deficits may be due to compensatory mechanisms such as induction of neurogenesis $(55,56)$, expression of neurotrophic factors such as BNDF (57) and conditioning effects (58). While the previous studies utilized relatively mild hypoxia, it is also feasible to administer brief periods of anoxia in a chronic-intermittent manner. One such paradigm caused specific cognitive and emotional deficits including reduced attention and increase in anxiety in absence of detectable structural damage (59).

\section{Chronic Continuous Hypoxia (CCH)}

Chronic continuous hypoxia models usually employ hypoxia in the range of $6-12 \% \mathrm{O}_{2}$ which is administered continuously on several consecutive days. Various behavioral phenotypes have been reported in $\mathrm{CCH}$ models including hyperactivity, increased aggression, and altered adult sexual behavior $(60,61) .10 \% \mathrm{O}_{2}$ $\mathrm{CCH}$ from $\mathrm{P} 1$ to $\mathrm{P} 20$ leads to reduced CA1 cell counts (60). 9.5\% $\mathrm{O}_{2} \mathrm{CCH}$ in P3-P11 rats causes ventriculomegaly and cortical thinning (62), findings also observed in human Sz patients (35). Our group, however, was not able to replicate these results in mice, possibly due to adaptive and conditioning effects described above (55) or higher hypoxia tolerance of the species (54). Moreover, a study reported an increased numbers of cortical neurons following chronic hypoxia of $9.5 \% \mathrm{O}_{2}(63)$, indicating reduced cell death or increased neurogenesis following the HI insult (64).

\section{Acute Hypoxia}

In these models, severe hypoxia or anoxia is administered. Depending on the oxygen content and insult duration, it is possible to model different conditions. $\mathrm{AH}$ of $3-4 \% \mathrm{O}_{2}$ for $15-20^{\prime}$ as well as $10^{\prime}$ of anoxia reliably induce seizures in rat pups $(65,66)$. Further effects are reduced CA1 cell density and behavioral abnormalities in early adulthood including hyperactivity, susceptibility to stress, disturbed motor coordination, and enhanced startle response (60, 67-69). However, some studies indicate that already a caesarian section alone may suffice to cause alterations in the dopamine system and vulnerability to stress (70). P1-P2 rat pups survived anoxia of up to $25^{\prime}$ without morphological changes, but developed hyperactivity and performed worse in passive avoidance tasks in later life (71). These deficits correlated to persistent abnormalities in monoamine systems and hyperresponsiveness to amphetamines and stress in later life $(72,73)$. They were rescued by blocking NMDAR with MK-801 before anoxia (71). By contrast, a short anoxia of $5^{\prime}$ was protective and induced neurogenesis in P1 rats (74). Birth anoxia furthermore induced persisting spatial memory deficits and altered expression of the calcium binding protein parvalbumin in interneurons of the hippocampus (28). Intriguingly, P8 in rats, neurodevelopmentally corresponding to approximately pre-birth human age, was found to be a highly vulnerable period (22). Few hours of $7-8 \% \mathrm{O}_{2}$ at this age leads to reduced brain growth, cortical thinning (22), alterations of the cholinergic, serotonergic, and dopaminergic systems, and disturbed sleep $(75,76)$.

\section{The Rice-Vannucci Model of HI (RVM)}

In most experimental paradigms, HI conditions are achieved using the RVM, first published in 1981 (77). In this model, unilateral ligation of one common carotid artery is followed by mild hypoxia in a sealed chamber. Due to sufficient collateralization, ligation itself does not lead to tissue damage. Only upon combination of ischemia and hypoxia, the oxygen and glucose supply to the ipsilateral hemisphere is compromised to a degree enough to evoke functional and structural deficits (78). The severity of injury depends on the duration and severity of hypoxia (79). A commonly used paradigm of $8 \% \mathrm{O}_{2}$ for up to $3 \mathrm{~h}$ leads to combined apoptotic and necrotic cell death in parts of the neocortex, hippocampus, striatum, and the white matter 
$(80,81)$. Importantly, the contralateral side appears unimpaired and can serve as internal control (82). The RVM gives rise to various behavioral phenotypes including motor deficits (81), sensory processing abnormalities (83), impaired spatial learning and memory $(81,84)$, and reduced attention (83-85). Interestingly, these deficits appear to be hemisphere specific and sex dependent as lesions of the right hemisphere were found to cause larger impairments in working memory tasks (86), while females with left occlusion presented greater spatial memory impairment and histological damage than males with left occlusion or females with right occlusion (21).

\section{DISCUSSION}

Perinatal HI brain damage can induce a broad variety of psychiatric and neurological symptoms, depending on the kind and severity of the insult and vulnerability of the system studied. Figure 1 gives a qualitative overview of $\mathrm{HI}$ effects depending on duration and severity of hypoxia. In light of the multitude of co-variables, it is hardly surprising that the same model may yield contradicting results. This variance may be reduced by thorough standardization of procedures. To address basic questions on the molecular, cellular, and local network levels and for studies of metabolism, in vitro models of HI may be more suitable because of better control or even exclusion of many of the environmental variables listed above $(87,88)$. As the local circuitry and cytoarchitecture are preserved in acute brain slices, they provide a tool to study the effects of $\mathrm{HI}$ within a frame of up to $12 \mathrm{~h}$, while organotypic slice cultures enable the study of chronic changes of up to 1 month (88-90). Despite all difficulties, perinatal $\mathrm{HI}$ models are valuable for $\mathrm{Sz}$ research, given a suitable model is employed to optimize specificity and construct validity, as many features of human patients can be mimicked. Therefore, instead of the question "whether," the question "which-HI model(s) is/are useful in Sz research," is more appropriate. Severe HI models are more widely employed in neurology while mild chronic continuous or intermittent hypoxia models are more established in psychiatry because of the desired lack of cell death in the latter. However, mild models suffer from higher variance in results and reduced reproducibility. We suppose that such mild insults may be on the watershed between causing subtle functional deficits and evoking compensatory protective effects via conditioning, gene expression, and periphery counterregulation mechanisms. Especially mild $\mathrm{CIH}$ models may succumb to these conditioning effects. HI alters expression of hundreds of genes, including BDNF (57) and amyloid precursor protein both in rodents and humans (91), which is supposedly part of an acute compensatory protective response, but may lead to dementia in later life (92). The neuroprotective effects of repetitive mild HI are well described in humans and animal studies (93). Transient HI induces tolerance to further $\mathrm{HI}$ insults and is subject of investigations as a possible therapeutical tool in neurological and cardiological clinical trials $(94,95)$. The translational potency of $\mathrm{AH}$ models in $\mathrm{P} 0-\mathrm{P} 1$ rodents is questionable, as this age neurodevelopmentally corresponds to the early second trimester in humans. On the other hand, mild CCH from P1 to P20 also hardly reproduces any human pathophysiological condition, translating to a human age of second trimester to late childhood. Therefore, we advocate the use a single $\mathrm{HI}$ insult in close resemblance to human condition in its core features such as duration and severity. As highlighted previously, it is furthermore crucial to use rodents at a proper developmental stage (P7-P8, corresponding to preterm infants or the third trimester or P9-P10 rodents, corresponding to the perinatal period) (16). While usually employed in neurological research, the RVM of HI may be successfully adapted for psychiatric models by titrating the insult (by reduction of hypoxia duration or elevation of the $\mathrm{O}_{2}$ concentration) in a way that focal necrosis does not occur. It may prove more reliable than pure hypoxia models as chronic adaptive effects could be circumvented. Compromised perfusion of the

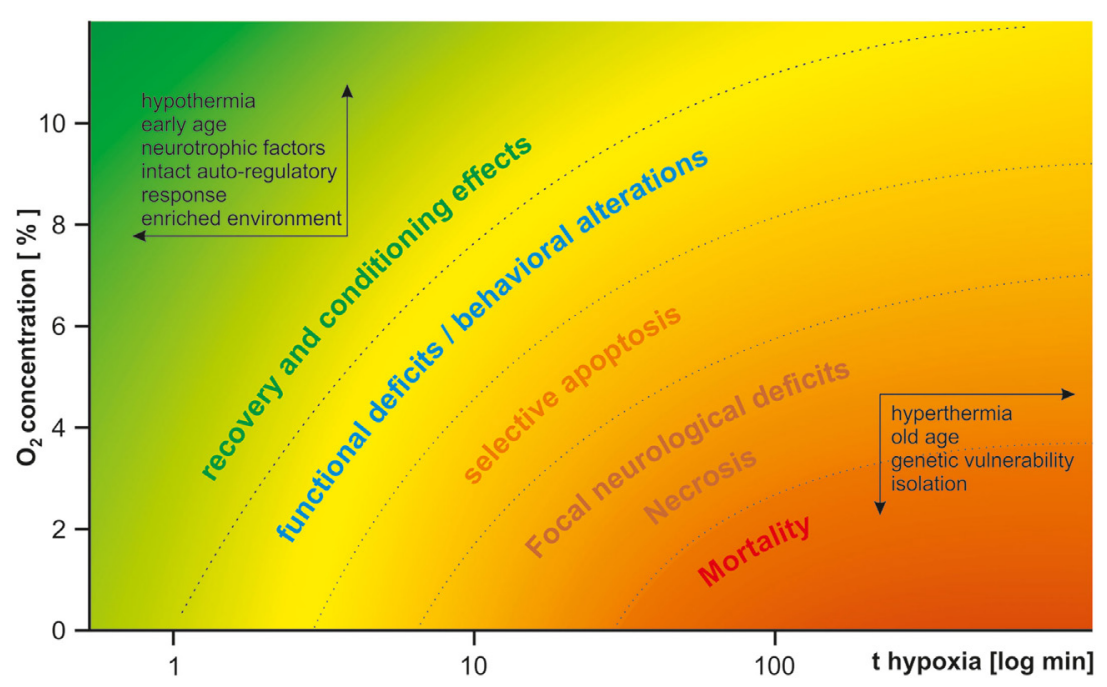

FIGURE 1 | Qualitative effects of hypoxia in dependence of severity and duration of the insult. The insult duration is drawn logarithmically on the $x$-axis. The oxygen concentration is drawn on the $y$-axis. Depending on both parameters, the insult either lacks long-lasting effects or is even protective (upper-left corner, green), or leads to functional and structural deficits (from yellow to orange) and mortality (bottom-right corner, red). Protective factors are listed within the arrows in the upper-left corner; harmful factors are listed within the arrows in the bottom-right corner. For psychiatric research, a mild type of insult in the yellow range needs to be carefully selected. 
brain combined with sub-necrotic hypoxia of several minutes to few hours appears to quite well reassemble human obstetric complications. Furthermore, the multifactorial etiology of the disease needs to be appreciated. Thus, perinatal insults constitute only one of multiple risk factors of Sz and may lead to its manifestation only in combination with hereditary vulnerability and further environmental stressors in later life. Therefore, development of two-hit or three-hit models should be sought in addition to the HI insult, including a pharmacologically or genetically induced risk constellation and environmental factors such as social stress or isolation.

\section{AUTHOR CONTRIBUTIONS}

DH, HM, PG, and DI contributed conception and design of the study; DH wrote the first and the revised drafts of the manuscript

\section{REFERENCES}

1. van Os J, Kapur S. Schizophrenia. Lancet (2009) 374:635-45. doi:10.1016/ S0140-6736(09)60995-8

2. Schmitt A, Malchow B, Hasan A, Falkai P. The impact of environmental factors in severe psychiatric disorders. Front Neurosci (2014) 8:19. doi:10.3389/ fnins.2014.00019

3. Zornberg GL, Buka SL, Tsuang MT. Hypoxic-ischemia-related fetal/neonatal complications and risk of schizophrenia and other nonaffective psychoses: a 19-year longitudinal study. Am J Psychiatry (2000) 157:196-202. doi:10.1176/ appi.ajp.157.2.196

4. Millar LJ, Shi L, Hoerder-Suabedissen A, Molnár Z. Neonatal hypoxia ischaemia: mechanisms, models, and therapeutic challenges. Front Cell Neurosci (2017) 11:78. doi:10.3389/fncel.2017.00078

5. Maynard TM, Sikich L, Lieberman JA, LaMantia A-S. Neural development, cell-cell signaling, and the "two-hit" hypothesis of schizophrenia. Schizophr Bull (2001) 27:457-76. doi:10.1093/oxfordjournals.schbul.a006887

6. Cannon TD, Yolken R, Buka S, Torrey EF; Collaborative Study Group on the Perinatal Origins of Severe Psychiatric Disorders. Decreased neurotrophic response to birth hypoxia in the etiology of schizophrenia. Biol Psychiatry (2008) 64:797-802. doi:10.1016/j.biopsych.2008.04.012

7. Schmidt-Kastner R, van Os J, Esquivel G, Steinbusch HWM, Rutten BPF. An environmental analysis of genes associated with schizophrenia: hypoxia and vascular factors as interacting elements in the neurodevelopmental model. Mol Psychiatry (2012) 17:1194-205. doi:10.1038/mp.2011.183

8. Fineberg AM, Ellman LM, Buka S, Yolken R, Cannon TD. Decreased birth weight in psychosis: influence of prenatal exposure to serologically determined influenza and hypoxia. Schizophr Bull (2013) 39:1037-44. doi:10.1093/ schbul/sbs084

9. Brown AS. The environment and susceptibility to schizophrenia. Prog Neurobiol (2011) 93:23-58. doi:10.1016/j.pneurobio.2010.09.003

10. Bouslama M, Adla-Biassette H, Ramanantsoa N, Bourgeois T, Bollen B, Brissaud $\mathrm{O}$, et al. Protective effects of intermittent hypoxia on brain and memory in a mouse model of apnea of prematurity. Front Physiol (2015) 6:313. doi:10.3389/fphys.2015.00313

11. Michiels C. Physiological and pathological responses to hypoxia. Am J Pathol (2004) 164:1875-82. doi:10.1016/S0002-9440(10)63747-9

12. Hasegawa K, Yoshioka H, Sawada T, Nishikawa H. Lipid peroxidation in neonatal mouse brain subjected to two different types of hypoxia. Brain Dev (1991) 13:101-3. doi:10.1016/S0387-7604(12)80115-X

13. Fontaine RH, Olivier P, Massonneau V, Leroux P, Degos V, Lebon S, et al. Vulnerability of white matter towards antenatal hypoxia is linked to a species-dependent regulation of glutamate receptor subunits. Proc Natl Acad Sci U S A (2008) 105:16779-84. doi:10.1073/pnas.0803004105

14. Hoshikawa Y, Nana-Sinkam P, Moore MD, Sotto-Santiago S, Phang T, Keith RL, et al. Hypoxia induces different genes in the lungs of rats compared with mice. Physiol Genomics (2003) 12:209-19. doi:10.1152/physiolgenomics.00081. 2001 and drew the figure. All the authors significantly contributed to manuscript revision, provided important intellectual content, and read and approved the submitted version.

\section{FUNDING}

This work was supported by grants from the Deutsche Forschungsgemeinschaft (IN 168/3-1) to DI and PG, the Ingeborg Ständer Foundation to DI, the Research Fund of the UPK Basel to DI, and the Physician Scientist Program of the Medical Faculty of the University of Heidelberg to DH. We acknowledge financial support by Deutsche Forschungsgemeinschaft within the funding program Open Access Publishing, by the Baden-Württemberg Ministry of Science, Research and the Arts and by University of Heidelberg.
15. Salmaso N, Jablonska B, Scafidi J, Vaccarino FM, Gallo V. Neurobiology of premature brain injury. Nat Neurosci (2014) 17:341-6. doi:10.1038/nn.3604

16. Clancy B, Finlay BL, Darlington RB, Anand KJS. Extrapolating brain development from experimental species to humans. Neurotoxicology (2007) 28:931-7. doi:10.1016/j.neuro.2007.01.014

17. Ben-Ari Y. Excitatory actions of GABA during development: the nature of the nurture. Nat Rev Neurosci (2002) 3:728-39. doi:10.1038/nrn920

18. Monyer H, Burnashev N, Laurie DJ, Sakmann B, Seeburg PH. Developmental and regional expression in the rat brain and functional properties of four NMDA receptors. Neuron (1994) 12:529-40. doi:10.1016/0896-6273(94)90210-0

19. Sheldon RA, Sedik C, Ferriero DM. Strain-related brain injury in neonatal mice subjected to hypoxia-ischemia. Brain Res (1998) 810:114-22. doi:10.1016/ S0006-8993(98)00892-0

20. Johnston MV, Hagberg H. Sex and the pathogenesis of cerebral palsy. Dev Med Child Neurol (2007) 49:74-8. doi:10.1111/j.1469-8749.2007.0199a.x

21. Sanches EF, Arteni NS, Nicola F, Boisserand L, Willborn S, Netto CA. Early hypoxia-ischemia causes hemisphere and sex-dependent cognitive impairment and histological damage. Neuroscience (2013) 237:208-15. doi:10.1016/j. neuroscience.2013.01.066

22. Slotkin TA, Cowdery TS, Orband L, Pachman S, Whitmore WL. Effects of neonatal hypoxia on brain development in the rat: immediate and long-term biochemical alterations in discrete regions. Brain Res (1986) 374:63-74. doi:10.1016/0006-8993(86)90395-1

23. Schmidt-Kastner R, Freund TF. Selective vulnerability of the hippocampus in brain ischemia. Neuroscience (1991) 40:599-636. doi:10.1016/ 0306-4522(91)90001-5

24. Kann O, Papageorgiou IE, Draguhn A. Highly energized inhibitory interneurons are a central element for information processing in cortical networks. J Cereb Blood Flow Metab (2014) 34:1270-82. doi:10.1038/jcbfm.2014.104

25. Freund TF, Buzsaki G, Leon A, Baimbridge KG, Somogyi P. Relationship of neuronal vulnerability and calcium binding protein immunoreactivity in ischemia. Exp Brain Res (1990) 83:55-66. doi:10.1007/BF00232193

26. Xie H, Leung KL, Chen L, Chan YS, Ng PC, Fok TF, et al. Brain-derived neurotrophic factor rescues and prevents chronic intermittent hypoxia-induced impairment of hippocampal long-term synaptic plasticity. Neurobiol Dis (2010) 40:155-62. doi:10.1016/j.nbd.2010.05.020

27. Rogalska J, Danielisova V, Caputa M. Effect of neonatal body temperature on postanoxic, potentially neurotoxic iron accumulation in the rat brain. Neurosci Lett (2006) 393:249-54. doi:10.1016/j.neulet.2005.09.085

28. Iuvone L, Geloso MC, Dell'Anna E. Changes in open field behavior, spatial memory, and hippocampal parvalbumin immunoreactivity following enrichment in rats exposed to neonatal anoxia. Exp Neurol (1996) 139:25-33. doi:10.1006/exnr.1996.0077

29. Tuor UI, Grewal D. Autoregulation of cerebral blood flow: influence of local brain development and postnatal age. Am J Physiol (1994) 267:H2220-8. doi:10.1152/ajpheart.1994.267.6.H2220

30. Caputa M, Rogalska J, Wentowska K, Nowakowska A. Perinatal asphyxia, hyperthermia and hyperferremia as factors inducing behavioural disturbances 
in adulthood: a rat model. Behav Brain Res (2005) 163:246-56. doi:10.1016/j. bbr.2005.05.015

31. Inta D, Monyer H, Sprengel R, Meyer-Lindenberg A, Gass P. Mice with genetically altered glutamate receptors as models of schizophrenia: a comprehensive review. Neurosci Biobehav Rev (2010) 34:285-94. doi:10.1016/j. neubiorev.2009.07.010

32. Nestler EJ, Hyman SE. Animal models of neuropsychiatric disorders. Nat Neurosci (2010) 13:1161-9. doi:10.1038/nn.2647

33. Mallard EC, Rehn A, Rees S, Tolcos M, Copolov D. Ventriculomegaly and reduced hippocampal volume following intrauterine growth-restriction: implications for the aetiology of schizophrenia. Schizophr Res (1999) 40:11-21. doi:10.1016/S0920-9964(99)00041-9

34. Hirjak D, Huber M, Kirchler E, Kubera KM, Karner M, Sambataro F, et al. Cortical features of distinct developmental trajectories in patients with delusional infestation. Prog Neuropsychopharmacol Biol Psychiatry (2017) 76:72-9. doi:10.1016/j.pnpbp.2017.02.018

35. Kelsoe JR Jr, Cadet JL, Pickar D, Weinberger DR. Quantitative neuroanatomy in schizophrenia. A controlled magnetic resonance imaging study. Arch Gen Psychiatry (1988) 45:533-41. doi:10.1001/archpsyc.1988.01800300029003

36. McNeil TF, Cantor-Graae E, Weinberger DR. Relationship of obstetric complications and differences in size of brain structures in monozygotic twin pairs discordant for schizophrenia. Am J Psychiatry (2000) 157:203-12. doi:10.1176/appi.ajp.157.2.203

37. Zierhut KC, Graßmann R, Kaufmann J, Steiner J, Bogerts B, Schiltz K. Hippocampal CA1 deformity is related to symptom severity and antipsychotic dosage in schizophrenia. Brain (2013) 136:804-14. doi:10.1093/brain/aws335

38. Sigurdsson T, Duvarci S. Hippocampal-prefrontal interactions in cognition, behavior and psychiatric disease. Front Syst Neurosci (2016) 9:190. doi:10.3389/ fnsys.2015.00190

39. Meyer-Lindenberg AS, Olsen RK, Kohn PD, Brown T, Egan MF, Weinberger DR, et al. Regionally specific disturbance of dorsolateral prefrontal-hippocampal functional connectivity in schizophrenia. Arch Gen Psychiatry (2005) 62:379-86. doi:10.1001/archpsyc.62.4.379

40. Gonzalez-Burgos G, Cho RY, Lewis DA. Alterations in cortical network oscillations and parvalbumin neurons in schizophrenia. Biol Psychiatry (2015) 77:1031-40. doi:10.1016/j.biopsych.2015.03.010

41. Uhlhaas PJ, Singer W. Abnormal neural oscillations and synchrony in schizophrenia. Nat Rev Neurosci (2010) 11:100-13. doi:10.1038/nrn2774

42. Turetsky BI, Calkins ME, Light GA, Olincy A, Radant AD, Swerdlow NR. Neurophysiological endophenotypes of schizophrenia: the viability of selected candidate measures. Schizophr Bull (2007) 33:69-94. doi:10.1093/schbul/ sbl060

43. Sigurdsson T. Neural circuit dysfunction in schizophrenia: insights from animal models. Neuroscience (2016) 321:42-65. doi:10.1016/j. neuroscience.2015.06.059

44. Hamm JP, Peterka DS, Gogos JA, Yuste R. Altered cortical ensembles in mouse models of schizophrenia. Neuron (2017) 94:153-67.e8. doi:10.1016/j. neuron.2017.03.019

45. Marín O. Interneuron dysfunction in psychiatric disorders. Nat Rev Neurosci (2012) 13:107-20. doi:10.1038/nrn3155

46. Taylor SF, Tso IF. GABA abnormalities in schizophrenia: a methodological review of in vivo studies. Schizophr Res (2015) 167:84-90. doi:10.1016/j. schres.2014.10.011

47. Howes OD, Kapur S. The dopamine hypothesis of schizophrenia: version III - the final common pathway. Schizophr Bull (2009) 35:549-62. doi:10.1093/ schbul/sbp006

48. Coyle JT. Glutamate and schizophrenia: beyond the dopamine hypothesis. Cell Mol Neurobiol (2006) 26:365-84. doi:10.1007/s10571-006-9062-8

49. Lang UE, Puls I, Muller DJ, Strutz-Seebohm N, Gallinat J. Molecular mechanisms of schizophrenia. Cell Physiol Biochem (2007) 20:687-702. doi:10.1159/000110430

50. Schmitt A, Fendt M, Zink M, Ebert U, Starke M, Berthold M, et al. Altered NMDA receptor expression and behavior following postnatal hypoxia: potential relevance to schizophrenia. J Neural Transm (2007) 114:239-48. doi:10.1007/s00702-006-0440-7

51. Fendt M, Lex A, Falkai P, Henn FA, Schmitt A. Behavioural alterations in rats following neonatal hypoxia and effects of clozapine: implications for schizophrenia. Pharmacopsychiatry (2008) 41:138-45. doi:10.1055/s-20081058107
52. Decker MJ, Hue GE, Caudle WM, Miller GW, Keating GL, Rye DB. Episodic neonatal hypoxia evokes executive dysfunction and regionally specific alterations in markers of dopamine signaling. Neuroscience (2003) 117:417-25. doi:10.1016/S0306-4522(02)00805-9

53. Boksa P, El-Khodor BF. Birth insult interacts with stress at adulthood to alter dopaminergic function in animal models: possible implications for schizophrenia and other disorders. Neurosci Biobehav Rev (2003) 27:91-101. doi:10.1016/S0149-7634(03)00012-5

54. Lima-Ojeda JM, Vogt MA, Richter SH, Dormann C, Schneider M, Gass P, et al. Lack of protracted behavioral abnormalities following intermittent or continuous chronic mild hypoxia in perinatal C57BL/6 mice. Neurosci Lett (2014) 577:77-82. doi:10.1016/j.neulet.2014.06.022

55. Fagel DM, Ganat Y, Silbereis J, Ebbitt T, Stewart W, Zhang H, et al. Cortical neurogenesis enhanced by chronic perinatal hypoxia. Exp Neurol (2006) 199:77-91. doi:10.1016/j.expneurol.2005.04.006

56. Tsai Y-W, Yang Y-R, Wang PS, Wang R-Y. Intermittent hypoxia after transient focal ischemia induces hippocampal neurogenesis and c-Fos expression and reverses spatial memory deficits in rats. PLoS One (2011) 6:e24001. doi:10.1371/journal.pone.0024001

57. Samoilov M, Churilova A, Gluschenko T, Rybnikova E. Neocortical pCREB and BDNF expression under different modes of hypobaric hypoxia: role in brain hypoxic tolerance in rats. Acta Histochem (2014) 116:949-57. doi:10.1016/j.acthis.2014.03.009

58. Rybnikova E, Vataeva L, Tyulkova E, Gluschenko T, Otellin V, Pelto-Huikko M, et al. Mild hypoxia preconditioning prevents impairment of passive avoidance learning and suppression of brain NGFI-A expression induced by severe hypoxia. Behav Brain Res (2005) 160:107-14. doi:10.1016/j.bbr.2004.11.023

59. Casolini P, Zuena AR, Cinque C, Matteucci P, Alema GS, Adriani W, et al. Sub-neurotoxic neonatal anoxia induces subtle behavioural changes and specific abnormalities in brain group-I metabotropic glutamate receptors in rats. J Neurochem (2005) 95:137-45. doi:10.1111/j.1471-4159.2005.03349.x

60. Mikati MA, Zeinieh MP, Kurdi RM, Harb SA, El Hokayem JA, Daderian $\mathrm{RH}$, et al. Long-term effects of acute and of chronic hypoxia on behavior and on hippocampal histology in the developing brain. Brain Res Dev Brain Res (2005) 157:98-102. doi:10.1016/j.devbrainres.2005.03.007

61. Hermans RH, McGivern RF, Chen W, Longo LD. Altered adult sexual behavior in the male rat following chronic prenatal hypoxia. Neurotoxicol Teratol (1993) 15:353-63. doi:10.1016/0892-0362(93)90051-O

62. Ment LR, Schwartz M, Makuch RW, Stewart WB. Association of chronic sublethal hypoxia with ventriculomegaly in the developing rat brain. Brain Res Dev Brain Res (1998) 111:197-203. doi:10.1016/S0165-3806(98)00139-4

63. Stewart WB, Ment LR, Schwartz M. Chronic postnatal hypoxia increases the numbers of cortical neurons. Brain Res (1997) 760:17-21. doi:10.1016/ S0006-8993(97)00271-0

64. Inta $\mathrm{D}$, Gass $\mathrm{P}$. Is forebrain neurogenesis a potential repair mechanism after stroke? J Cereb Blood Flow Metab (2015) 35:1220-1. doi:10.1038/jcbfm.2015.95

65. Jensen FE. An animal model of hypoxia-induced perinatal seizures. Ital J Neurol Sci (1995) 16:59-68. doi:10.1007/BF02229075

66. Sampath D, Shmueli D, White AM, Raol YH. Flupirtine effectively prevents development of acute neonatal seizures in an animal model of global hypoxia. Neurosci Lett (2015) 607:46-51. doi:10.1016/j.neulet.2015.09.005

67. Shimomura C, Ohta H. Behavioral abnormalities and seizure susceptibility in rat after neonatal anoxia. Brain Dev (1988) 10:160-3. doi:10.1016/ S0387-7604(88)80020-2

68. Dell'Anna ME, Calzolari S, Molinari M, Iuvone L, Calimici R. Neonatal anoxia induces transitory hyperactivity, permanent spatial memory deficits and CA1 cell density reduction in developing rats. Behav Brain Res (1991) 45:125-34. doi:10.1016/S0166-4328(05)80078-6

69. El-Khodor BF, Boksa P. Transient birth hypoxia increases behavioral responses to repeated stress in the adult rat. Behav Brain Res (2000) 107:171-5. doi:10.1016/S0166-4328(99)00119-9

70. El-Khodor B, Boksa P. Caesarean section birth produces long term changes in dopamine D1 receptors and in stress-induced regulation of D3 and D4 receptors in the rat brain. Neuropsychopharmacology (2001) 25:423-39. doi:10.1016/S0893-133X(01)00228-7

71. Speiser Z, Uziel J, Defrin-Assa R, Gitter S, Urca G. Different behavioral deficits are induced by anoxia/hypoxia in neonatal and senescent rats: blockade by MK-801. Behav Brain Res (1991) 42:181-6. doi:10.1016/ S0166-4328(05)80009-9 
72. Dell'Anna ME, Luthman J, Lindqvist E, Olson L. Development of monoamine systems after neonatal anoxia in rats. Brain Res Bull (1993) 32:159-70. doi:10.1016/0361-9230(93)90070-R

73. Juarez I, Silva-Gomez AB, Peralta F, Flores G. Anoxia at birth induced hyperresponsiveness to amphetamine and stress in postpubertal rats. Brain Res (2003) 992:281-7. doi:10.1016/j.brainres.2003.08.060

74. Blaise SA, Nedelec E, Alberto J-M, Schroeder H, Audonnet S, BossenmeyerPourie C, et al. Short hypoxia could attenuate the adverse effects of hyperhomocysteinemia on the developing rat brain by inducing neurogenesis. Exp Neurol (2009) 216:231-8. doi:10.1016/j.expneurol.2008.11.020

75. Tanaka H, Takahashi S, Miyamoto A, Oki J, Cho K, Okuno A. Effects of neonatal hypoxia on brainstem cholinergic neurons-pedunculopontine nucleus and laterodorsal tegmental nucleus. Brain Dev (1995) 17:264-70. doi:10.1016/0387-7604(95)00043-B

76. Hadjiconstantinou M, Yates AJ, Neff NH. Hypoxia-induced neurotransmitter deficits in neonatal rats are partially corrected by exogenous GM1 ganglioside. J Neurochem (1990) 55:864-9. doi:10.1111/j.1471-4159.1990.tb04571.x

77. Rice JE, Vannucci RC, Brierley JB. The influence of immaturity on hypoxic-ischemic brain damage in the rat. Ann Neurol (1981) 9:131-41. doi:10.1002/ ana.410090206

78. Vannucci RC, Vannucci SJ. Perinatal hypoxic-ischemic brain damage: evolution of an animal model. Dev Neurosci (2005) 27:81-6. doi:10.1159/000085978

79. Towfighi J, Zec N, Yager J, Housman C, Vannucci RC. Temporal evolution of neuropathologic changes in an immature rat model of cerebral hypoxia: a light microscopic study. Acta Neuropathol (1995) 90:375-86. doi:10.1007/ BF00315011

80. Drobyshevsky A, Derrick M, Wyrwicz AM, Ji X, Englof I, Ullman LM, et al. White matter injury correlates with hypertonia in an animal model of cerebral palsy. J Cereb Blood Flow Metab (2007) 27:270-81. doi:10.1038/sj.jcbfm.9600333

81. Balduini W, De Angelis V, Mazzoni E, Cimino M. Long-lasting behavioral alterations following a hypoxic/ischemic brain injury in neonatal rats. Brain Res (2000) 859:318-25. doi:10.1016/S0006-8993(00)01997-1

82. Vannucci RC, Yager JY. Glucose, lactic acid, and perinatal hypoxic-ischemic brain damage. Pediatr Neurol (1992) 8:3-12. doi:10.1016/ 0887-8994(92)90045-Z

83. Alexander M, Garbus H, Smith AL, Rosenkrantz TS, Fitch RH. Behavioral and histological outcomes following neonatal HI injury in a preterm (P3) and term (P7) rodent model. Behav Brain Res (2014) 259:85-96. doi:10.1016/j. bbr.2013.10.038

84. Buwalda B, Nyakas C, Vosselman HJ, Luiten PG. Effects of early postnatal anoxia on adult learning and emotion in rats. Behav Brain Res (1995) 67:85-90. doi:10.1016/0166-4328(94)00108-R

85. Miguel PM, Schuch CP, Rojas JJ, Carletti JV, Deckmann I, Martinato LHM, et al. Neonatal hypoxia-ischemia induces attention-deficit hyperactivity disorder-like behavior in rats. Behav Neurosci (2015) 129:309-20. doi:10.1037/ bne 0000063
86. Arteni NS, Salgueiro J, Torres I, Achaval M, Netto CA. Neonatal cerebral hypoxia-ischemia causes lateralized memory impairments in the adult rat. Brain Res (2003) 973:171-8. doi:10.1016/S0006-8993(03)02436-3

87. Hefter D, Kaiser M, Weyer SW, Papageorgiou IE, Both M, Kann O, et al. Amyloid precursor protein protects neuronal network function after hypoxia via control of voltage-gated calcium channels. J Neurosci (2016) 36:8356-71. doi:10.1523/JNEUROSCI.4130-15.2016

88. Schurr A, Payne RS, Miller JJ, Rigor BM. Study of cerebral energy metabolism using the rat hippocampal slice preparation. Methods (1999) 18:117-26. doi:10.1006/meth.1999.0765

89. Noraberg J, Poulsen F, Blaabjerg M, Kristensen B, Bonde C, Montero M, et al. Organotypic hippocampal slice cultures for studies of brain damage, neuroprotection and neurorepair. Curr Drug Targets CNS Neurol Disord (2005) 4:435-52. doi:10.2174/1568007054546108

90. Kann O. The energy demand of fast neuronal network oscillations: insights from brain slice preparations. Front Pharmacol (2012) 2:90. doi:10.3389/ fphar.2011.00090

91. Baiden-Amissah K, Joashi U, Blumberg R, Mehmet H, Edwards AD, Cox PM. Expression of amyloid precursor protein (beta-APP) in the neonatal brain following hypoxic ischaemic injury. Neuropathol Appl Neurobiol (1998) 24:346-52. doi:10.1046/j.1365-2990.1998.00141.x

92. Hefter D, Draguhn A. APP as a protective factor in acute neuronal insults. Front Mol Neurosci (2017) 10:22. doi:10.3389/fnmol.2017.00022

93. Vijayakumar NT, Sangwan A, Sharma B, Majid A, GK R. Cerebral ischemic preconditioning: the road so far.... Mol Neurobiol (2016) 53:2579-93. doi:10.1007/s12035-015-9278-Z

94. Liebeskind D, Saver J, Gonzalez NR. Preconditioning for acute stroke. Clin Neurol Neurosurg (2013) 115:2124-9. doi:10.1016/j.clineuro.2013.07.038. Peripheral

95. England TJ, Hedstrom A, O’Sullivan S, Donnelly R, Barrett DA, Sarmad S, et al. RECAST (Remote Ischemic Conditioning after Stroke Trial): a pilot randomized placebo controlled phase II trial in acute ischemic stroke. Stroke (2017) 48:1412-5. doi:10.1161/STROKEAHA.116.016429

Conflict of Interest Statement: The authors declare that the research was conducted in the absence of any commercial or financial relationships that could be construed as a potential conflict of interest.

Copyright (c) 2018 Hefter, Marti, Gass and Inta. This is an open-access article distributed under the terms of the Creative Commons Attribution License (CC $B Y)$. The use, distribution or reproduction in other forums is permitted, provided the original author(s) and the copyright owner are credited and that the original publication in this journal is cited, in accordance with accepted academic practice. No use, distribution or reproduction is permitted which does not comply with these terms. 